halves and Number $8 \mathrm{~s}(2.6 \%)$. The most common injury location was the ankle $(21.4 \%)$ and $42.9 \%$ of ankle injuries were suffered by Locks. There was a significant association $(p=0.010)$ between player position and injury location. In contrast, no significant associations $(p>0.05)$ were observed between player position and contact injury, contact event or injury type.

Conclusions The Lock position was more prone to injury than any other position during SLUG 2019 but the majority of the players were injured regardless of the playing position. Thorough physical conditioning and skill practice could be key areas of concern to reduce injuries in university-level rugby.

\section{RELATIONSHIP BETWEEN BALANCE AND LOWER EXTREMITY ROM, H/Q RATIO, HAMSTRING TIGHTNESS, BEIGHTON SCORE IN PROFESSIONAL FOLK DANCERS AND PROFESSIONAL FOOTBALL PLAYERS}

${ }^{2}$ Busra Akgonul, ${ }^{1}$ Vefa Atansay, ${ }^{1}$ Ayhan Nedim Kara, ${ }^{3}$ Azmi Hamzaoglu, ${ }^{1}$ Neslihan Aksu. ${ }^{1}$ Demiroglu Bilim University Medical Facuty Florence Nightingale Hospital Orthopedics and Traumatology Department, Istanbul, Turkey; ${ }^{2}$ Sisli Florence Nightingale Hospital Physical Therapy and Rehabilitation Department, Istanbul, Turkey; ${ }^{3}$ Istanbul Florence Nightingale Hospital Orthopaedic and Spine Center, Istanbul, Turkey

\subsection{6/bjsports-2021-IOC.231}

Background One of the factors of performance is to be agile that would require combination of speed, balance, power and coordination. Balance analysis is often used as an indication of risk of frequent injuries. In most of the sports, proprioceptive education programs are adapted to prevent lower extremity functional injuries.

Objective We aimed to determine the difference in balance between professional dancers and professional footballers and its relationship with lower extremity ROM, muscle strength (hip abductor- adductor, quadriceps, hamstring), H/Q ratio, hamstring tightness (Sit and reach, Straight Leg Raise (SLR) test), hypermobility test (Beighton score).

Design Prospective comparative study.

Setting Professional folk dancers (Fire of Anatolia Dance Group) and Premier League football players.

Patients (or Participants) Volunteered 20 professional folk dancers and 20 Premier League football players

Interventions (or Assessment of Risk Factors) Hamstring tightness, decreased ROM, Beighton score (smaller or equal of 3 , greater or equal of 5) is the risk factor for static and dynamic balance decrease.

Main Outcome Measurements SportKAT 4000 (Kinesthetic Ability Trainer) measurements $(\mathrm{p}<0,005)$ are better in dancers (eyes open with both feet, right leg only, left leg only, eyes closed both feet, eyes open dynamic both feet) compare to athletes.Active $\mathrm{ROM}$ angles $(\mathrm{p}<0,005)$ are significantly higher in dancers' hip, knee and ankle compare to athletes. Our findings showed that dancers' Beington score was 3,8 \pm 3 and athletes' score was $2,5 \pm 1,5$. Hamstring lenght in dancers was $95,5 \pm 10$ and athletes was $76,6 \pm 7,1$.

Results Dancers' static and dynamic balances $(\mathrm{p}<0,005)$ are significantly better than athletes. $\mathrm{H} / \mathrm{Q}$ ratios are not different between dancers and athletes; however, dancers' Hamstring length $(\mathrm{p}<0,005)$ is higher compare to athletes.

Conclusions Decreased flexibility and ROM cause lesser resistance to perturbation and balance problems. We think that dancer are better in static and dynamic balances compare to athletes due to greater ROM degrees and Hamstring flexibility.

\section{RISK MANAGEMENT THROUGH AN ASSERTIVE PRESEASON ASSESSMENT}

${ }^{1}$ Natália FN Bittencourt, ${ }^{1}$ Renato de Paula da Silva, ${ }^{1}$ Paola de Figueiredo Caldeira, ${ }^{2}$ Robson José Rodrigo Tavares de Almeida, ${ }^{2}$ Jomar Jorge Ottoni, ${ }^{2}$ Gustavo Damásio Magliocca, 1,3Luciana De Michelis Mendonça. 'PHAST - Physiotherapy Assessment Tool, Belo Horizonte, Brazil; ${ }^{2}$ Sociedade Esportiva Palmeiras, São Paulo, Brazil; ${ }^{3}$ UFVJM - Universidade Federal dos Vales do Jequitinhonha e Mucuri, Diamantina, Brazil

\subsection{6/bjsports-2021-IOC.232}

Background Preseason assessment is common in sports teams and aims to analyze athletes' physical and functional parameters. These data assist physical therapists to develop global and individualized injury prevention programs and to identify any improvement throughout the season.

Objective To determine predictors for musculoskeletal injuries in youth male soccer athletes.

Design Cohort study.

Setting One youth soccer team facility.

Patients (or Participants) One hundred sixteen young male soccer athletes.

Interventions (or Assessment of Risk Factors) All data were collected in two days. Athletes were aleatory selected to perform the tests and the physical therapists, previously trained, applied the following tests: single leg hamstring bridge (SLHB), bridge test with unilateral knee extension, passive hip internal rotation (IR) range of motion (ROM), hip abductor strength, hamstring flexibility and composite score of Y-Test. Considering it could have an interference in other tests, Y-Test were the last measure in all athletes. Injuries were collected throughout the season.

Main Outcome Measurements any lower limb (LL) injury occurring during scheduled games or practices that cause an athlete to miss a subsequent game or practice session.

Results The Classification and Regression Trees (CART) model identified as predictors of LL injuries in youth soccer athletes: SLHB, bridge test with unilateral knee extension, passive hip internal rotation ROM, hip abductors strength, hamstrings flexibility and composite score of Y-Test result. The model had an accuracy of $76 \%(p<.0001)$ and the correct classification was $88.6 \%$ for injury and $56.6 \%$ for non-injury.

Conclusions The SLHB, bridge test with unilateral knee extension, passive hip internal rotation ROM, hip abductors strength, hamstrings flexibility and composite score of Y-Test should be included in pre-season assessment in youth soccer athletes. The results of these tests could be used as parameters to develop a prevention program in soccer.

\section{PRE-SEASON CLINICAL ASSESSMENT OF THE HIP EXTENSORS, EXTERNAL ROTATORS AND ABDUCTORS IN COMPETITIVE SPRINTERS}

\footnotetext{
${ }^{1,2}$ Pedro Luiz Flores Fagnani, $3,4,5$ Natália FN Bittencourt, ${ }^{2}$ Fabian Peralta. ${ }^{1}$ EUSES/UdG/ University of Barcelona (U.B.), Barcelona, Spain; ${ }^{2}$ FisioDeportiva, Barcelona, Spain ${ }^{3}$ Department of Public Health of EMGO + Institue at the VU University Medical Center, Amsterdam, Netherlands: ${ }^{4}$ Uni Bh University, Belo Horizonte, Brazil; ${ }^{5}$ Phast App, Belo Horizonte, Brazil
}

10.1136/bjsports-2021-IOC.233 